\title{
Examining the Effect of Motivational Factors on Productivity of Human Resources in the Education
}

\author{
Omolbanin Hashemi Gorji (Corresponding author) \\ Department of Educational Psychology, Islamic Azad University, Shahrekord Branch, Iran \\ E-mail: mirzajanihassan@yahoo.com
}

Meysam Rajaby Kookandeh

Department of Humane Resource Management, Islamic Azad University, Iran

\section{Ali Akbar Kamalifar}

PhD Candidate of philosophy in management, Lincoln University in Malaysia

\section{Hassan Razaghi Shani}

Department of Management Lincoln University College Malaysia, Branch Iran

Mehraneh Delaviz Bayekolaei

Department of Education, University Malaya, Kuala Lumpur, Malaysia

\section{Reza Alami}

Department of Management Lincoln University College Malaysia, Branch Iran

Received: June 04, 2016 Accepted: June 21, 2016 Published: July 10, 2016

doi:10.5296/ijhrs.v6i2.9564 URL: http://dx.doi.org/10.5296/ijhrs.v6i2.9564

\begin{abstract}
Human resources are considered as the most valuable and important factor for development of every country. In the Education system which its goal is to educate the future generation and to act in providing the educated work forces, there are several effective factors which among them the role of teachers is the most important and outstanding. Productivity and
\end{abstract}


efficiency of these forces depends on different factors which among them we can refer to being timely of teachers' training and using the latest technologies and teaching skills and their motivation. This project has examined the effective factors on increasing teachers' efficiency and the role of job motivation among human forces. The research results show that lack of knowledge and sufficient skills are considered as a decreasing factor and motivation as the main increasing factor of productivity in teachers. Also they show that in-service training periods haven't been successful in fulfilling this demand yet. One suggestion for coping these issues is adjusting teachers' higher education with in demand branches and fields. Furthermore, motivating teachers should be done with different material and spiritual forces, and their encouragement be in line with their struggling.

Keywords: Productivity, Motivation, In-service trainings, Higher education

\section{Introduction}

In any organization, human forces are considered as one of the most important existing sources. How to use the human sources as optimized is an important factor for efficiency of the organization. Optimization in using work forces in the Education is an important basis for developing of different countries; since the bases of education- creative, trained and responsible human forces which are the leader of development and growth of any society- are initially established in this system. Since productivity is an organizational factor which can guarantee the stability and survival of each organization and a mechanism for acquiring the competitive advantage; so, what is leads to productivity of human sources in the organization is that the staff- in terms of personality, interests and emotions- are adapted to their organizational activities and jobs (Mirkamali, 1997). In this way, interest, motivation and responsibility and thus the organizational productivity, directly and indirectly, is improved. Undoubtedly, human sources have an important contribution in economic, social and cultural development of any society. In fact, human sources are the most important basis of each organization; since the nature our movement is towards development and growth. Staff participation in the affairs and their consciously efforts with job discipline can be effective on the productivity and improvement of an organization. The feeling of productivity improving should be inspired within the organization among which "human sources" are the central part. In optimization, it is sought to examine the existing situation in terms of using less sources and acquiring more products in order to identify the existing flaws and deficiencies and try to optimize the existing situation with our achievements in technology and science (Amiran, 1993).

\section{Statement of the Problem}

Human resources are considered as the most important production factor in an organization, and the most important factor in failing organizations is lack of having necessary skills in human communication. The goal of an organization should be educating humans who can face with problems and solve them by their creative thoughts (Aghaee Feishaee,1993).

Because one of the keys for being successful in the organizations is exchanging 
knowledge-and experience-based information between humans. Motivation is created if the staff has the feeling of security and job stability, effective participation and contribution in the organization. Motivation is a state within the humans which tends them toward a particular behavior and action. Discussing to meet the needs and supportive factors, more effectiveness of the staff and create a hot and good atmosphere in the organizations attracts the attention of any concerned and farsighted person (Schultz \& Schultz, 2012). Only with effort, sympathy and harmony of all groups and organizations of a society, we can naturally hope that the country goes toward development and progress. So, there is always this question: why and how creating motivation and meeting the logical needs of the teachers has positive effect on their job attachment and increasing their morale; and on the contrary, how much the weakness of an organization has negative effect on the staff's motivation and morale? Why are some teachers in the schools active and motivated despite of equal facilities? How do the teachers use their maximum effort? How can we increase their job morale? However, there are many different factors creating motivation within the people, and answering to these questions is possible by identifying what motivate the teachers.

\section{Conception and Definition of Productivity}

The term of "productivity" has different meanings from different views: More efficiency a long with a fixed cost, doing affairs correctly, doing affairs more carefully and more honestly, and automating the operations for acquiring more efficiency. In Education, productivity means: The relation between the manner of using the present resources by the educational organization and changing it to the optimal outputs through an educational process along with considering the quality of life of its all staff (Mirkamali, 1997). Educational productivity is considered as the relation between inputs (the costs in training) and outputs (educational progress or other defined goals for the Education). The main point in the educational productivity is "cost effectiveness" and how to use the present resources for improvement of students' progress. In this way, we should consider educational planning and financial issues as an effective and necessary factor on the productivity. In the Education, productivity is defined as the relation between students' educational progress and the present resources. The common point of all these definitions is the importance of students and increasing their abilities, and also optimal using of the present resources and reducing the costs of activities doing for improvement of productivity (IranZadeh, 1994).

\section{The Importance and Role of Human Forces in Productivity and Efficiency of Educational System}

The most important resource within any organization is human force. The constituent factors of this force are the emotional and logical beings who serve their aptitude and skills for the organization if there is sufficient motivation. To Gardner (1985), even the best reconstruction of the Education ends with failure if the quality and quantity of teachers aren't met sufficiently. In the Education, the most important role is related to the human forces, and the teachers are considered as the most effective factors on qualitative growth and development of education; because educating humans is the result of a mutual interrelation and the product of a trainer's actions and a trainee's reaction. The teacher as a trainer can have a key role in 
this relation: he able to educate the creative and efficient human forces who cause the growth and integrity of the society.

Students look carefully all the behaviors of the teachers, the principal and even the servant of the school and learn from them. Students learn from the behavior and interaction of the teachers with the principal, among the teachers, the teachers with the servant of the school and the teachers with the students. The teacher is not just a teacher, he is a powerful trainer and model.

Many people are working within the educational process setting, and their activities effect on the students' training directly or indirectly. However, the role of teachers among other people is more dominant. Since the students spend most of their time they are at school with the teachers, many of students under classical and modern educational system owe their personality to their teachers (Davoudi, 2009).

In the education process, what is transferred to the learner is not only the teacher's skills and knowledge, but also his personality, behaviors and moods are transferred too. Student-teacher interaction is a kind of spiritual relation. The student considers his or her teacher as a respectable and elite character who helps him or her in becoming an adult and independent person and one of the formal member of the society.

Teachers deal with the life and spirit of students, so they are accepted as a beloved model (Jasbi, 1991). Children and adolescents are formally accepted among a new society i.e. the school when they go out their family. In this new society, students have the opportunity to review their previous behaviors and habits and their religions thoughts and establish their personality. The most powerful and beloved person who can help them during this sensitive step is the teacher, so students accept their teacher as a model and pattern his or her bad or good behaviors and consider their teachers as equal with themselves (LeBoeuf,1986).

\section{Strategies for Improvement of Motivation and Productivity of Human Forces in the Education}

It is not a long time since the strategies of improvement of quality and productivity have been employed in industrial and economic sectors. The success of these strategies in economic development encouraged the authors to experience them in the most fundamental social-economic system-the Education. Using the strategies of productivity improvement in educational systems has been successful. Productivity improvement in the Education not only helps to social-economic development, but also cause to uplifting of the country by educating creative and efficient human forces. Since educating which is the final goal of the educational system is a qualitative concept, evaluating the extent of productivity of human forces is also difficult. Most of educational experts believe that all leader countries in social-economic development have improved the quality and productivity of their Education (IranZadeh,1994). So, applying the advantages of improving productivity has an important role in social-economic development. There are many different factors creating motivation in people and cause improving the productivity: 


\subsection{Salary and Earning}

The paid salary of the staff should provide the necessary motivation within them. In other words, the staff should understand the amount of salary related to his done works. In the payment system of a governmental sector, the increase of staff's salary is usually fixed and equal and it is done annually, so there is no relation with the staff's operation in practice. Many studies show a relation between salary and increase of efficiency and productivity (Mortazavi, 1993). What is considered as a motivational criterion in staff's salary is finding the salary fair and impartial from the view of the staff. One of the important factor for increasing the productivity is a payment system which the staff considers it just and impartial. Generally, based on Equity Theory, people examine their inputs (education-level, experience, effort and loyalty) and the outputs receive from the organization (among which salary is the most important), and them by comparing them with others' outputs and comparing their inputs with others' inputs, they motivate if feeling justice (Berkowitz, 1984).

\subsection{Encouragement and Reward}

Staff should be received a reasonable reward for doing affairs as demanded and also for continuing doing affairs as better. The managers are rarely aware of the effectiveness of reward, even small, on staff's performance. Many studies show that not being rewarded for the job performance reduces the continuation of doing affairs as demanded.

Managers may believe that staffs' paid salary is a good reward for them. It is true that salary is an important factor in staff's performance, but the staff wants different rewards for their performance. Reward can be martial and non-martial (Ojaghi, 2001). Reward may include many simple things including: smiling, word thanking, nodding, etc.... The managers should develop the desired performance in the organization by using different rewards and motives.

\subsection{Existence of a precise evaluation system and valuing of workful teachers' works}

Generally, encouragement is an important factor in creating motivation. It should be noted that encouragement is subject to a person who is really deserving. The unwise and unjust encouragement not only doesn't increase the efficiency of those deserving persons, but it certainly has an inverse result. So, we should have some applicable and precise evaluating regulations and the evaluator should be aware of it and do justice. Education is a qualitative issue and evaluating it is an especial difficult work. A teacher who has sufficient and updated knowledge in his job field should be encouraged. He should know the latest teaching methods and apply them in practice. He should be considered as a positive model for the learners in terms of personality, morals and behaviors.

In many cases, the principal's considerateness in selecting deserving teachers and or using this in favor of those persons who aren't the most deserving ones have resulted in reverse results. There is another point: encouragement should be proportionate to the action (Shayan, 1996). Reward is effective if the man considers it as important. To award an appreciation paper is an old effective but insufficient way. Encouragements should have a material equal so that their effects become observable as soon as possible. 


\subsection{Training}

Training is one of the most complicating duties in managing of all organizations, especially in managing of human forces. One another factor which has a significant effect on the productivity is training. Some studies show that there is a strong positive correlation between training and productivity (IranZadeh, 1994). Undoubtedly, training is one of the most important measurements of all organizations. The educational system is complementary of the employment system, it causes to enable human forces and guarantee the future success. Training leads to the deeper knowledge, higher wisdom and greater skills in the employed person for performing the entrusted duties to him and it helps meet the organization's goals with more and better efficiency and effectiveness.

To LeBoeuf (1986), good training reduces job dissatisfaction and duplication and help staff works with his all capacity. These important goals won't be met unless all members of the organization be aware of the importance of training. The modern Techniques of improving productivity can't be effectively applied without presence of the trained human forces in all levels of the organization. Comparative studies on economic development between different countries showed that a country with trained human forces have profited by a higher productivity and economic growth.

\subsection{Applying Technology}

Selecting and applying the appropriate technology as an instruments, machinery, methods and other tools for producing goods or services is effective on reduces the costs and increasing the outputs of an organization. The technology world is increasingly changing and developing. Today generation faces with a mass of information surrounding him. The curious mind of adolescents and the necessity of answering to the questions which are asked as the result of facing with findings and situations related to the modern developments require that our teachers adapt themselves with modern knowledge. The results of scientific studies on teaching methods and specialized knowledge in different scientific fields show that a teacher not only should have sufficient knowledge and skill in the beginning of his work, but also he should continuously be adopted with modern findings and technologies.

\subsection{In-service Courses}

Within our country's educational system, there are some teachers who aren't aware of modern findings after many years of teaching officially and they still teach with the knowledge they had at the time of completing their education. The necessity for continuous training of teachers has been always perceived by the Education administrators. Although In-service courses are various and done with different quality in different provinces, we should accept this bitter fact that they haven't had the sufficient efficiency yet. One of the main problems of these courses which leads to the low efficiency of in-service courses is weakness in selecting the professors of these courses (Destjerd, etal., 2008). Unfortunately, those deserving persons with high education degrees don't agree to work because of the paltry fees of these courses and or despite of their tendency, they aren't applied because of some managerial weaknesses. Another point is that in-service courses are considered as a margin not as a component of a 
teacher's work. These courses are often organized during un-useful times or in holidays, so the participants don't focus on the lessons.

\subsection{Higher Education}

To pass formal educational courses at universities is a way which has been recently received gladly by the teachers and the government has provided the necessary facilities in past years. This was effective on improving teacher's specialized knowledge and increasing their productivity, but there have been some weaknesses; For example, mismatching of their academic fields and employment demands. So despite of spending cost and time, they couldn't use their knowledge and degrees for meeting teaching needs. Some teachers educated in the fields in which we have excess work forces. If our teachers' education is planned, the educational system can reduce the training cost of its staff and trains them by the cost of other systems.

\section{Discussion and Conclusion}

Considering teachers' motivational factors and their needs and considering individual differences of all teachers are two important factors we can achieve them in productivity of human forces. One important element for achieving to our goal in any work is "creating motivation in those who do that" (IranZadeh, 1994). One of attitude changes for teachers is related to "motivation level". Motivation is defined as: the reason of doing behaviors and the first cause of meeting individuals' needs. Motivation is considered as a behaviour which determines the intensity, orientation and sustainability of a person in achieving to a goal (Robbins, 1979). The authors believe that the motivated teachers have more tendency to present at school and they are more active in teaching. We can expect that the motivated teachers struggle for meeting their needs. It should be noted that we need productivity of staff in the organization; so we should improve the motivational factors among them.

One important challenge in any organization is changing of awarding ways which motivate human forces. Less a person earns money, more the importance of money becomes. More a person earns money and more a person sympathizes with his work, less the importance of money becomes, and to him, money is replaced by the faculty of recognition for achieving to goals and independence. As the same, the competition between the deserving persons becomes more. Material incentives can't alone attract the honest persons. For those who don't have material concerns, the feeling of welfare is more important than money. There are some factors influencing on the welfare: human communication, mutual confidence, feeling of being worthed, and feeling of justice. Furthermore, the opportunity for learning new subjects and understanding individual aptitude help create a positive feeling among individuals. Positive motives which meet both material and spiritual needs of people are more effective than the negative motives which are expressed as punishments or threats (LeBoeuf, 1986).

Health and joy are two other effective factors on creating motivation. When a teacher feels health and happiness, he becomes tired and ill less, finds his job pleasant and works with more motivation. According to the studies, the cost of securing health and happiness of the staff in order to increase productivity won't be more than the cost of curing and 
non-profitability of the staff as the result of their weakness. One another important point in encouraging teachers to do better and create motivation among them is related to "the ways of occupational and organizational promotion".

The studies show that those promotions are based on factors other than the staff's ability and efficiency often leads to a false result. Those who are at managing level should be aware of their real abilities and accept those tasks which are in line with their abilities. This mystery makes the job pleasant and increases one's efficiency. It should be noted that the staff's abilities and capacities are properly measured at every level and the ways of progress are examined and followed. In this way, the capacities should be increased by evaluating and achieving to a conclusion. So, sustainable evaluation of the teachers' performance while on duty is very necessary. The main reasons for performance evaluation include: identifying good teachers and granting reward to them and thus creating motivation among them for improving their performance (Ojaghi, 2001). We can use the information obtaining from the teachers' performance evaluation for planning human forces, selecting and training teachers, determining occupational trend, salary and extra pays, and identifying the potentials. The last motive which we study is the teaching process. The teacher is considered as a model for students; so the personality, scientific ability, and teaching skills of the teacher is the main effective factor on students who are the final output. The goal of education is that by increasing occupational knowledge or by teaching special skills, persons' behavior and attitude changes toward achieving the organizational goal. To do this, any organization should have a group of deserving and efficient staff (Marguis, 1999). Therefore, it is necessary that those employing in the Education system pass some specialized and professional training courses along with their formal general training. Training is not just for the inexperienced persons, but the experienced staff should be passed in-service training when necessary. All teachers, in fact, should be trained continuously in order to have the most efficiency and productivity (Jafari, 2002). One of the primary objectives in any training course is creating a true view toward the job and educational system. It is expected that teachers reach to a deep understanding at the end of the course which changes their behavior toward an effective cooperation with education system and their minds tend to support the goals of the Education.

\section{References}

Akbari, M. (2007). Reviews the awareness of the administrators of the management functions and its relationship to professional success in high schools. Master's thesis. Islamic Azad University Gachsaran.

Alaghe band, A. (1999). Public Management. Nasher Ravan Publication, Tehran, Iran.

Alaghe band, A. (2009). Educational Management. Nasher Ravan Publication, Tehran, Iran.

Mirkamali, S.M. (1994). Management and Educational Leadership. Amin Publication, Tehran, Iran.

Mousavi, S.F. (2006). The survey of managers' knowledge to their professional duties. Unpublished master's thesis. Islamic Azad University of Sari. 


\section{Macrothink}

International Journal of Human Resource Studies

ISSN 2162-3058 2016, Vol. 6, No. 2

Nadimi, M, T. (2001). Education in elementary, middle and high school. Mehrdad Publication, Tehran, Iran.

Niknami, M. (1995). The concepts of efficiency and effectiveness of educational managers. Quarterly Journal of Management Number 15.

Rezaeaian,A.(1994). Principles of Management. Samt Publication, Tehran, Iran.

Rezayee, M. (2005). Evaluate the performance of public and private principals. Unpublished master's thesis. Islamic Azad University of Sari.

Seyed Javadein,(2006). Human resources management. Negah Publication, Tehran, Iran

Tahmasbzade,S,(2008). Factors that influence on management achieving in educational objectives. Unpublished master's thesis. Islamic Azad University of Sari.

Tosi, M.A. (2006). Management and Educational Leadership. Kohsar Publication, Tehran, Iran

Zarrin Mehr,M.(1999). Study of training demands Secondary School Principals seven areas of Mashhad. Master's thesis. Islamic Azad University of Mashhad.

Zirak,M.(1997). Compare the performance of the managers of educational management in the Boy's High School graduate. Unpublished master's thesis. Islamic Azad University of Mashhad.

\section{Copyright Disclaimer}

Copyright for this article is retained by the author(s), with first publication rights granted to the journal.

This is an open-access article distributed under the terms and conditions of the Creative Commons Attribution license (http://creativecommons.org/licenses/by/3.0/). 